Monthly Progress Report

Heat Source Technology Program

June 1993

Compiled by

T. G. George 


\title{
MONTHLY PROGRESS REPORT HEAT SOURCE TECHNOLOGY PROGRAM \\ JUNE 1993
}

\author{
CONTENTS
}

ABSTRACT $\quad$............................................................... 1

I. HEAT SOURCE AND FEED POWDER SHIPMENTS $\ldots \ldots \ldots \ldots \ldots \ldots \ldots \ldots . \ldots \ldots$

II. IRIDIUM HARDWARE SHIPMENTS AND INVENTORY .................... 1

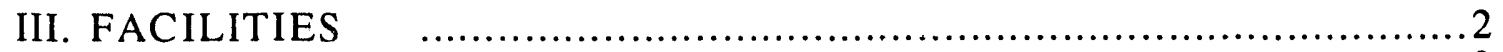

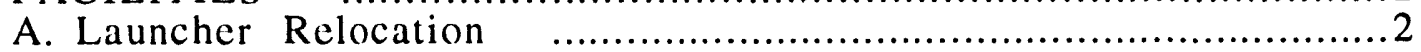

1. Construction Activities .............................................. 2

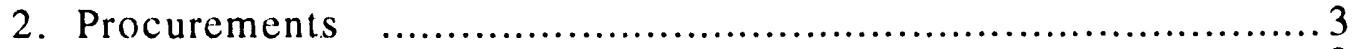

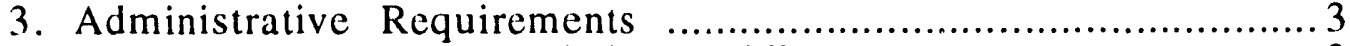

B. Glovebox for GPHS Encapsulation Welding ............................. 3

C. Metallography and Ceramography Glovebox Lines ......................... 3

D. Sieve Analysis Gloveboxes ......................................... 4

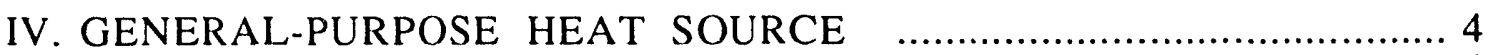

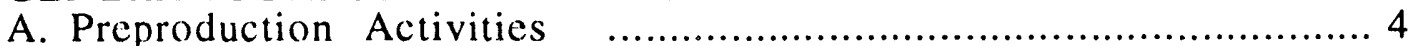

1. Operational Readiness Evaluation (ORE) ............................. 4

2. GPHS Fuel Powder, Pellet, and Fueled-Clad Specifications .............. 4

3. Development of Process Procedures .................................... 4

4. Fueled-Clad Weld Development ................................... 4

5. Fueled-Clad Ultrasonic Test Development $\ldots \ldots \ldots \ldots \ldots \ldots \ldots \ldots \ldots \ldots . . . \ldots 5$

6. Cold Process Verification (CPV) Tests ..................................... 5

7. Production Qualification .......................................... 7

B. Cassini Fueled-Clad Production .......................................... 7

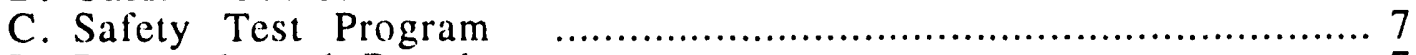

D. Research and Development .............................................. 7

1. High-Temperature Mechanical Properties of Urania Fuel Simulant ........ 7

2. High-Temperature Mechanical Properties of Graphite .......................7

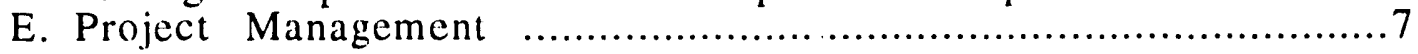

IV. LIGHT-WEIGHT RADIOISOTOPE HEATER YINIT (LWRHU) .................7

A. LWRHU Fuel Powder, Pellet, and Fueled Capsule Specifications .............. 7

B. LWRHU Weld Development ............................................... 7

C. LWRHU Production ................................................ 8

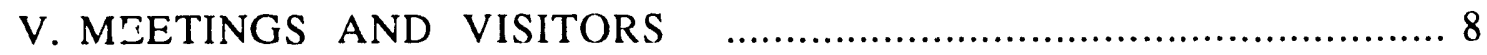




\title{
MONTHLY PROGRESS REPORT \\ HEAT SOURCE TECHNOLOGY PROGRAM \\ JUNE 1993
}

Compiled by

T. G. George

\begin{abstract}
This monthly report describes activities performed in support of Cassini fueled-clad production and studies related to the use of ${ }^{238} \mathrm{PuO}_{2}$ in radioisotope power systems carried out for the Office of Special Applications of the US Department of Energy (DOE) by Los Alamos National Laboratory (LANL). Most of the activities described are ongoing; the results and conclusions described may change as the work progresses.
\end{abstract}

\section{HEAT SOURCE AND FEED POWDER SHIPMENTS}

In mid-May, LANL received a PAT- 1 cask that contained six fuel samples from the former Soviet Union. The fuel samples were analyzed to verify that the stated quantities of nuclear material were correct. All verification measurements were complete by 1 June. However, additional analytical work was delayed by a semiannual inventory of special nuclear materiais (SNMs).

A shipment of recharacterization fuel was received from Westinghouse Savannah River Company (WSRC) at the beginning of the month and was placed in storage pending completion of the SNM inventory (expected by $6 \mathrm{July}$ ). The amount of $238 \mathrm{Pu}$ received in this shipment $(1.2 \mathrm{~kg})$ is sufficient to produce 9 GPHS fuel pellets, assuming an overall process yield $\geq 84 \%$.

\section{IRIDIUM HARDWARE SHIPMENTS AND INVENTORY}

A shipment of 10 General-Purpose Heat Source (GPHS) weld shields (type-II) was received from Martin Marietta Energy Systems (MMES) Y-12 on 22 June.

The amount of GPHS hardware a'vailable for the Cassini mission (at LANL), as of June 30, is shown in Table $I$. 
Table I. LANL Inventory of Cassini GPHS Iridium Hardware

Type of

Hardware

PiCS*

PICS
Category

Prime

Restricted
Number of Items

in Inventory

25

18

Type II Weld Shields

Prime

7

\section{FACILITIES}

\section{A. Launcher Relocation}

During June, work continued on construction of an addition to PF-4 to house the relocated launcher and on a number of related procurements.

\section{Construction Activities}

The second level of the launcher addition's interior and exterior walls was poured (to the 18-ft level) last month. In June, all of the structural steel and rebar assemblies required for the top two levels of the launcher addition were installed. Additional seismic isolation material was also placed between the third level of the launcher addition and the wall of building PF-4. By the end of the month, approximately $50 \%$ of the gang forms for the third concrete lift (an elevation of approximately $30 \mathrm{ft}$ ) had been emplaced.

At the end of June, chemical analysis of a cement sample that had been prepared by the concrete supplier at the time of the first concrete pour revealed that the cement contained approximately $6 \%$ more lime than the maximum permitted by American Society for Testing and Materials (ASTM) specifications for portland cement. Although a nonconformance report was written, all mechanical tests of concrete actually used in the addition have exceeded specifications. In addition, existing documentation has shown that the excess lime content would have no effect on corrosion of the steel reinforcements or on aging of the concrete. Finally, the cement sample submitted for chemical analysis is not directly traceable to the concrete used in the launcher addition.

Installation of electrical services for the heating, ventilation, and air conditioning (HVAC) system was temporarily suspended in mid-May, pending the resolution of issues associated with integrating these services into the PF-4 central control and distribution system. At the end of June a meeting was held between representatives from the user group, Heat Source Technology (NMT-9), the Technical Area (TA)-55 Facilities Management group (NMT-8), LANL's Facilities Engineering Division (ENG), and the building contractor to determine how the two systems would interface. All interface issues were resolved at this meeting and ENG personnel were tasked with revising design drawings for the addition. Work on installation of HVAC electrical services was expected to resume by mid-July. 
Duct hangers for the addition's HVAC system were seismically qualified early in June. By the end of the month, installation of the hangars had begun.

\section{Procurements}

The Laboratory's Materiais Management (MAT) Division had previously issued a purchase request (PR) for blast doors to cover both entryways from PF-4 into the launcher addition. By the end of June, MAT had concluded a purchase agreement for procurement of the blast doors. As part of this agreement, the vendor was tasked with supervising door installation.

The vendor selected for procurement and installation of the bridge crane had previously provided shop drawings of the proposed crane. The drawings were approved and the vendor was instructed to to proceed with fabrication of the crane.

A PR for the filter train that will be used in the launcher addition's HVAC system was previously forwarded to MAT division for placement.

Bids from system integrators for fabrication of the Supervisory Control System (SCS) that will control launcher operations were received on 27 April. Issuance of a purchase agreement continued to be delayed by a federal audit of MAT operations.

\section{Administrative Requirements}

Work began on revising launcher safe operating procedures (SOPs) and writing training plans.

\section{B. Glovebox for GPHS Encapsulation Welding}

Installation of the glovebox designed for GPHS encapsulation welding was completed in May 1992. A Safcty and Technical Assessment for Readiness of Technology (START) review of the welding operation was completed in mid-September 1992 and approval for process start-up was received on 21 September. However, because LANL may not be in compliance with current National Emissions Standards for Hazardous Air Pollutants (NESHAPS), a temporary limit was imposed that permitted only six fueled-clads to be welded each month.

The results of legal and managerial reviews completed in April indicated that a maximum oi $2.5 \mathrm{~kg}$ of $238 \mathrm{Pu}$ could be processed each month without exceeding the established TA-55 baseline. On this basis of this finding, it was determined that there are no NESHAPS implications for welding up to 16 fueled-clads per month.

\section{Metallography and Ceramography Glovebox Lines}

All of the gloveboxes in the metallography and ceramography lines have been installed and wired for electric power. A bench-top metallographic facility for "cold" (uncontizninated) specimens was activated previously and has been used to support fueled-clad weld-process development.

By the end of June work on a facility ventilation upgrade (to service open-front hoods in the ceramography and metallography glovebox lines) was essentially complete. Efforts to leak test the duct instal!ation were underway, and the ventilation upgrade was expected to be operational by mid-July. 


\section{Sieve Analysis Gloveboxes}

Two gloveboxes designed to house the sieving and particle size analysis operations were previously installed and prepared for use. NMT-9 requested a START review of these gloveboxes on 9 April, and a START review team convened on 30 April. On the basis of an inspection, the START review team identified 11 findings that would have to be addressed before the gloveboxes were approved for use. By the end of June, actions had been taken to close out all findings associated with the START review.

\section{GENERAL-PURPOSE HEAT SOURCE}

\section{A. Preproduction Activities}

\section{Operational Readiness Evaluation (ORE)}

A Cassini production ORE was conducted at LANL on 16-20 November 1992. Also present was a DOE Environment \& Health audit/review team that acted in an oversight capacity. The ORE was closed out on 20 November, with six findings to be resolved prior to the start of Cassini heat source production. By the end of May, the work required to close all six findings had been completed.

\section{GPHS Fuel Powder. Pellet, and Fueled-Clad Specifications}

The ${ }^{238} \mathrm{PuO}_{2}$ fuel powder acceptance specification, the GPHS fuel pellet specification, and the GPHS fueled-clad specification were previously distributed to the Office of Special Applications (OSA), EG\&G MAT, General Electric Astro Space (GE-ASTRO), Oak Ridge National Laboratory (ORNL), and WSRC for review, as required by the Interface Working Agreement (IWA). Six organizations/individuals provided comments on the draft specifications by the deadline of 7 May. These comments will be addressed in subsequent specification revisions.

\section{Development of Process Procedures}

Two compilations of procedures, titled "Quality Assurance Procedures for Flight Quality Cassini Fucled-Clads" and "Fabrication Procedures for Flight-Quality Cassini Fueled Clads" were previously distributed on controlled-copy bases internally and externally as required by the IWA. Both compilations will be updated to reflect subsequent procedure revisions only after DOE/OSA approval.

Sets of controlled-copy compilations of the "Fabrication Procedures for Flight-Quality Cassini Fueled Clads" were previously distributed to members of the Cassini Process Readiness Evaluation Review, which occurred on 18-19 May.

\section{Fueled-Clad Weld Development}

Three $238 \mathrm{PuO}_{2}$ fuel pellets were successfully encapsulated on 29 June. All three capsules were assembled with Type II (final design) weld-shields. Initial postweld examination did not reveal any weld defects or anomalies, and all of the capsules easily passed through the acceptance ring gauge. The time required to perform these three welds (which included assembly,welding, disassembly, and required quality assurance operations) was one h. 
The fuel pellet welded into the second capsule (FCO004) had previously fractured into three pieces. All of the weld equipment and assembly hardware performed as designed, and there were no problems positioning the three-piece pellet in the weld-shield cup.

In the next month, the three capsules welded on 29 June (FC0003, FC0004, FC0005) will be decontaminated, leak checked, ultrasonically tested, dimensioned, analyzed to determine the neutron emission rate, and metallographically examined to verify the presence of an acceptable weld microstructure.

\section{Fueled-Clad Ultrasonic Test Development}

On 15 April, LANL hosted a meeting of the GPHS Welding/Ultrasonic Testing (UT) Working Group. The primary outcome of this meeting, which was attended by representatives from NE-53, WSRC, EG\&G MAT, MMES, Westinghouse Advanced Energy Systems (WAES), GE-ASTRO, and Fairchild Space Company (FSC), was the development of a detailed plan and schedule to ensure that a viable UT system would be in place and operational by 15 July 1993 . By the end of June, all of the actions required by this plan were on schedule.

In early June, MMES-Y 12 personnel indicated that major modifications to the Cassini-UTinspection system software were complete and that a plan had been developed for required hardware modifications. On 9 June, MMES-Y 12 personnel trained a LANL UT technician on implementation and use of the modified UT inspection system.

\section{Cold Process Verification (CPV) Tests}

The CPV test series was designed to verify that the welding process for simulant-fueled ("cold") capsules had been optimized and to quantify the impact responses of the hotpressed, and cold-pressed and sintered, urania fuel-simulants.

All simulant-fucled clads required for the CPV test series were welded previously. Eight capsules were loaded with hot-pressed urania (235U-depleted) fuel-simulant and seven capsules were loaded with cold-pressed urania. UT examination performed with the existing Panametrics system indicated that the welds in nearly three-quarters of the capsules (11 of 15) contained indications that exceeded the proposed 4.8 equiv.-mils acceptance criterion.

a. CPV-1. On 28 September 1992, the first impact in the CPV series was completed. In this test (CPV-1), capsule SCOO11, which had been loaded with a hot-pressed urania pellet, was impacted against a steel plate at $55.0 \pm 1.0 \mathrm{~m} / \mathrm{s}$ and $1092^{\circ} \mathrm{C}$. The iridium hardware used for this capsule was Z-batch material produced for the Galileo and Ulysses missions. Postimpact examination of capsule SCO011 revealed that the clad had breached as a result of a fuel fragment push-through. Details of the clad failure, metallographic examination of selected clad sections, and a sieve analysis of fuel retained in the capsule were documented in previous monthly reports.

In this month, particle sizing of fines released from capsule SCO011 and of the $\leq 45 \mu \mathrm{m}$ fraction of the retained fuel-simulant was delayed by a START review of the sieve analysis gloveboxes (see Section IIID).

b. CPV-2. On 4 December 1992, capsule SC0008, which had been loaded with a hotpressed urania pellet, was impacted against a steel plate at $55.0 \pm 1.0 \mathrm{~m} / \mathrm{s}$ and $1090^{\circ} \mathrm{C}$. The iridium hardware used for this capsule was designated as "Prime" and was from the 
D2 batch. Postimpact examination revealed that although the capsule had two small transverse cracks on the cup radii at the edges of the impact face, no urania had been released. Details of the clad deformation and a sieve analysis of fuel retained in the capsule were documented in previous monthly reports.

In this month we continued to examine metallographic sections cut from capsule SCOO()8.

c. CPV-3. On 26 February 1993, capsule SCO004, which had been loaded with coldpressed and sintered urania fuel-simulant, was impacted against a steel plate at $55.0 \pm 0.1$ $\mathrm{m} / \mathrm{s}$ and $1090^{\circ} \mathrm{C}$. The iridium hardware used for this capsule was designated as "Prime" and was from the D2 batch.

Postimpact examination revealed that although the capsule contained two small transverse cracks on the cup radii at the edges of the impact face, no urania had been released. Details of this initial examination were documented in previous monthly reports.

In this month we made no progress on the CPV -3 postmortem examination.

d. CPV-4. On 5 March, capsule SCO020, which had been loaded with cold-pressed and sintered urania fuel simulant, was impacted against a steel plate at $55.3 \pm 0.2 \mathrm{~m} / \mathrm{s}$ and $1090^{\circ} \mathrm{C}$. The iridium hardware used for this capsule was X-and YR-batch material (vent cup ID, X342-2; shield cup ID, YR421-1) produced for the Galileo and Ulysses missions.

Postimpact examination revealed that capsule $\mathrm{SC} 0020$ had been breached by several cracks: an axial crack located approximately $120 \mathrm{deg}$ from the weld start that extended from the shield cup, through the weld, and into the vent cup; smaller axial weld cracks at 170,180 , and $225 \mathrm{deg}$; a network of hairline (generally axial) cracks at $\approx 180$ deg that extended from the edge of the grit blast line to the vent cup radius; and sinall transverse cracks on the cup radii at the edges of the impact face. A small amount of urania was released into the tantalum containment vessel. Details of this initial examination were given in previous monthly reports.

In this month we made no progress on the CPV -4 postmortem examination.

e. CPV-5. On 15 June, capsule SCO017, which had been loaded with cold-pressed and sintered urania, was impacted against a steel plate at $55.3 \pm 0.1 \mathrm{~m} / \mathrm{s}$ and $1090^{\circ} \mathrm{C}$. The iridium hardware for this capsule was designated as "Prime" and was from the D2 batch.

By the end of June, no progress had been made on the CPV-5 postmortem.

f. CPV-6. On 29 June, capsule SC(0)18, which had been loaded with cold-pressed and sintered urania, was impacted against a steel plate at $55.0 \pm 1.0 \mathrm{~m} / \mathrm{s}$ and $1\left(190^{\circ} \mathrm{C}\right.$. The iridium hardware used for this capsule was designated as "Prime" and was from the CR3 batch.

g. CPV-7. Capsule SCO019, loaded with cold-pressed and sintered urania, was selected for use in CPV-7. The iridium hardware used for this capsule was X-and YR-batch material (vent cup ID, X340-4; shield cup ID, YR42\%-6) produced for the Galileo and Ulysses missions. 


\section{Production Qualification}

On 18-19 May, the Cassini Process Readiness Evaluation Team conducted a preliminary review of LANL operations. Previously, LANL had completed a review of the 14 April draft readiness plan for the Production Qualification Program and had forwarded a copy of this review to the leader of the Process Readiness Evaluation Team.

A shipment of recharacterization fuel was received from WSRC at the beginning of June and was placed in storage pending completion of the SNM inventory (expected by 6 July). The amount of $238 \mathrm{Pu}$ received in this shipment $(1.2 \mathrm{~kg})$ is sufficient to produce nine GPHS fuel pellets, assuming an overall process yield $\geq 84 \%$.

\section{B. Cassini Fueled-Clad Production}

There was no activity during June.

\section{Safety Test Program}

There was no activity during June.

\section{Research and Development}

\section{High-Temperature Mechanical Properties of Urania Fuel Simulant}

There was no activity during June.

\section{High-Temperature Mechanical Properties of Graphite}

There was no activity during June.

\section{E. Project Management}

All required weekly status reports were delivered on schedule. The program Project Management System (PMS) monthly status report (which included a data disk) was also delivered to FSC (the operator of the program PMS) on schedule.

\section{LIGHT-WEIGHT RADIOISOTOPE HEATER UNIT (LWRHU)}

\section{A. LWRHU Fuel Powder, Pellet, and Fueled Capsule Specifications}

A draft version of the LWRHU product index was previously distributed to OSA, EG\&G MAT, GE-ASTRO, ORNL, and WSRC, for approval, comment, or information as described in the IWA. A final version of the LWRHU product index has not been released.

\section{B. LWRHU Weld Development}

A plexiglass welding chamber designed for "cold" weld process development has been fabricated and is expected to be installed by 15 July 1993. 


\section{LWRHU Production}

Fabrication of urania (235U-depleted) fuel-simulant pellets for two LWRHU vibration tests and for weld development was initiated at the end of May. The urania pellets were expected to be complete by mid July.

A vacuum furnace for high-temperature outgassing of assembled LWKHUs was brought online in June, and will be first used for outgassing of vibration test assemblies.

\section{MEETINGS AND VISITORS}

On 3 June, the Defense Nuclear Facilities Safety Board (DNFSB) convened at LANL to conduct a review of recent ${ }^{238} \mathrm{PuO}_{2}$-related skin contamination incidents. DOE was represented at this review by personnel from the Los Alamos, Albuquerque, and Germantown offices.

On 9 June, a safety expert from the DOE-Albuquerque office visited LANL to conduct a second review of recent ${ }^{238} \mathrm{PuO}_{2}$-related skin contamination incidents.

An internal LANL Safeguards and Security review was performed on 10 June.

On 11 June, a LANL UT technician attended a training session at MMES-Y12.

During the week of 14 June, two DOE/DP-42 personnel reviewed LANL's waste processing operations.

One LANL engineer supported a meeting at Teledyne Energy Systems in Timonium, Maryland, on 23 June to discuss potential heat source applications.

On 29-30 June, a WSRC welding engineer visited LANL to assist in the hot-weld development effort. 

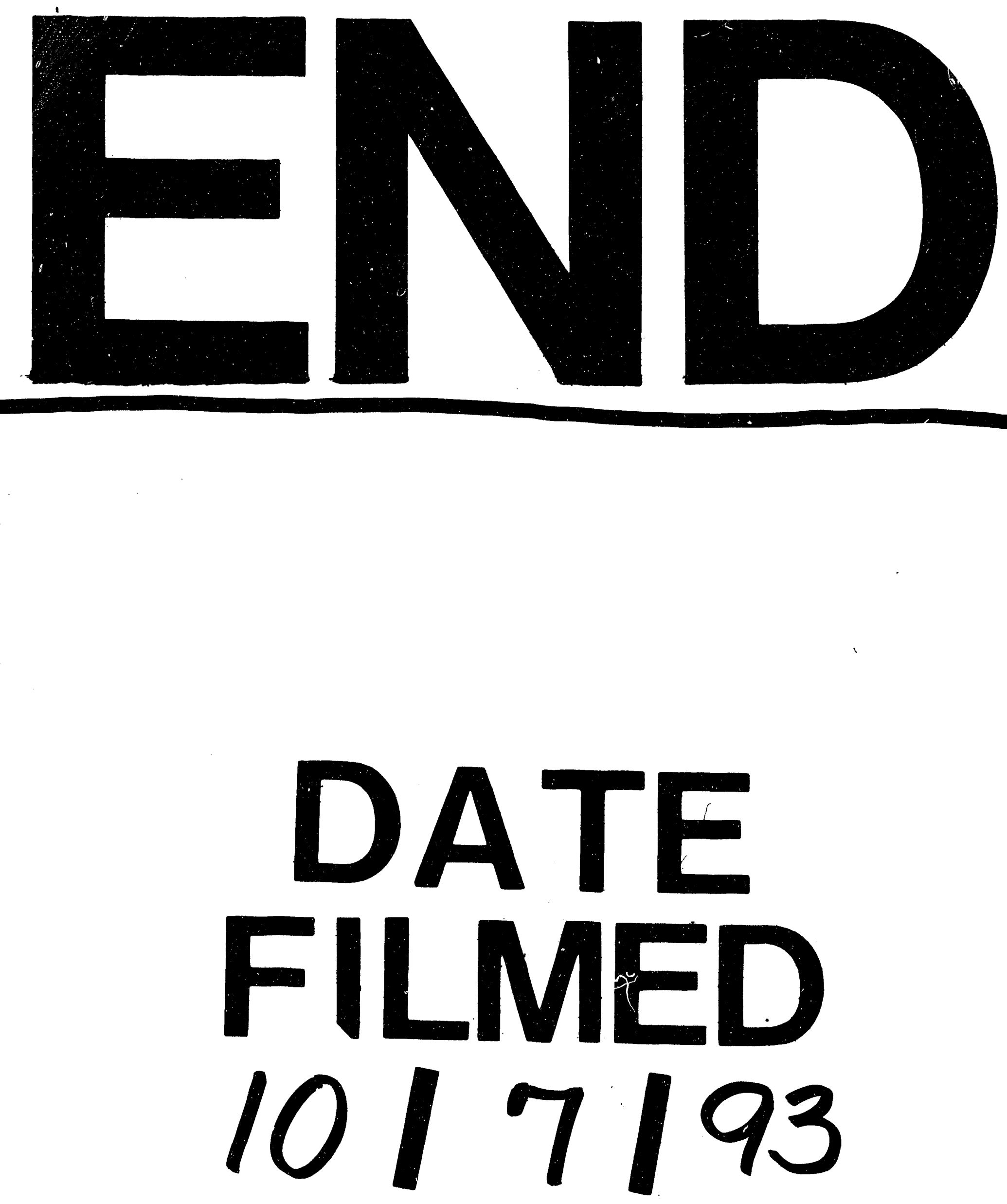
